\title{
Root causes and outcomes of postoperative pulmonary complications after abdominal surgery: a retrospective observational cohort study
}

Antero Fernandes ${ }^{1,2}$, Jéssica Rodrigues ${ }^{3}$, Patrícia Lages ${ }^{4}$, Sara Lança ${ }^{2}$, Paula Mendes ${ }^{5}$, Luís Antunes ${ }^{3}$, Carla Salomé Santos ${ }^{6}$, Clara Castro ${ }^{3,7}$, Rafael S. Costa ${ }^{8,9}$, Carlos Silva Lopes $^{10}$, Paulo Matos da Costa ${ }^{4}$ and Lúcio Lara Santos ${ }^{1,6,10^{*}}$ (D)

\begin{abstract}
Background: Postoperative pulmonary complications (PPCs) contribute significantly to overall postoperative morbidity and mortality. In abdominal surgery, PPCs remain frequent. The study aimed to analyze the profile and outcomes of PPCs in patients submitted to abdominal surgery and admitted in a Portuguese polyvalent intensive care unit.

Methods: From January to December 2017 in the polyvalent intensive care unit of Hospital Garcia de Orta, Almada, Portugal, we conducted a retrospective, observational study of inpatients submitted to urgent or elective abdominal surgery who had severe PPCs. We evaluated the perioperative risk factors and associated mortality. Logistic regression was performed to find which perioperative risk factors were most important in the occurrence of PPCs.

Results: Sixty patients (75\% male) with a median age of 64.5 [47-81] years who were submitted to urgent or elective abdominal surgery were included in the analysis. Thirty-six patients (60\%) developed PPCs within $48 \mathrm{~h}$ and twenty-four developed PPCs after $48 \mathrm{~h}$. Pneumonia was the most frequent PPC in this sample. In this cohort, 48 patients developed acute respiratory failure and needed mechanical ventilation. In the emergency setting, peritonitis had the highest rate of PPCs. Electively operated patients who developed PPCs were mostly carriers of digestive malignancies. Thirty-day mortality was $21.7 \%$. The risk of PPCs development in the first $48 \mathrm{~h}$ was related to the need for neuromuscular blocking drugs several times during surgery and preoperative abnormal arterial blood gases. Median abdominal surgical incision, long surgery duration, and high body mass index were associated with PPCs that occurred more than $48 \mathrm{~h}$ after surgery. The American Society of Anesthesiologists physical status score 4 and COPD/Asthma determined less mechanical ventilation needs since they were preoperatively optimized. Malnutrition (low albumin) before surgery was associated with 30-day mortality.
\end{abstract}

Conclusion: PPCs after abdominal surgery are still a major problem since they have profound effects on outcomes. Our results suggest that programs before surgery, involve preoperative lifestyle changes, such as nutritional supplementation, exercise, stress reduction, and smoking cessation, were an effective strategy in mitigating postoperative complications by decreasing mortality.

Keywords: Abdominal surgery, Acute respiratory failure, Mechanical ventilation, Polyvalent intensive care unit, Postoperative pulmonary complications, Risk score

\footnotetext{
*Correspondence: Ilarasantos@gmail.com

'Experimental Pathology and Therapeutics Group, Instituto Português de

Oncologia, Porto, Portugal

${ }^{6}$ Surgical Oncology Department of Portuguese Instituto Português de

Oncologia, Porto, Portugal

Full list of author information is available at the end of the article
}

(c) The Author(s). 2019 Open Access This article is distributed under the terms of the Creative Commons Attribution 4.0 International License (http://creativecommons.org/licenses/by/4.0/), which permits unrestricted use, distribution, and reproduction in any medium, provided you give appropriate credit to the original author(s) and the source, provide a link to the Creative Commons license, and indicate if changes were made. The Creative Commons Public Domain Dedication waiver (http://creativecommons.org/publicdomain/zero/1.0/) applies to the data made available in this article, unless otherwise stated. 


\section{Background}

Nearly 234 million patients undergo major surgery worldwide every year [1]. Approximately $16 \%$ will suffer a complication within 30 days [2]. In 2015, the European Perioperative Clinical Outcome (EPCO) standardized the concept of postoperative complications (POCs) in the various organ systems, which constitutes an important advance in perioperative medicine [3]. One set of under-reported complications are postoperative pulmonary complications (PPCs) that are costly and increase patient mortality. After abdominal surgery (AS), PPCs are one of the most important causes of postoperative morbidity and mortality $[4,5]$. Various perioperative risk factors are related to their appearance in the postoperative period [6]. Physiological changes in the respiratory system that occur immediately after the induction of general anesthesia explain the majority of POCs [7]. Thus, respiratory drive and muscle function are altered, lung volumes reduced, and atelectasis develops in more than $75 \%$ of patients receiving neuromuscular blocking drugs (NMBD). The respiratory system may take 6 weeks to return to its preoperative state after general anesthesia for major surgery [8]. Acute respiratory failure (ARF) is common in intensive care settings and classified by some studies as a PPC on its own, and in some patients its severity that may lead to the need for mechanical ventilation (MV) as a method of respiratory support [9]. Previous respiratory pathology, obesity, and nutritional deficits also contribute significantly to the occurrence of respiratory complications in the postoperative period. Some of these factors are modifiable [10,11]. Facing the magnitude of PPCs, performing an early identification of surgical patients at risk for ARF would allow to intervene in an earlier and most useful time, increasing the survival of these patients [12-17]. The American Society of Anesthesiologists physical status (ASA PS) and ARISCAT score (for PPCs), while effective risk prediction tools, can help reduce morbidity and mortality $[18,19]$. However, there are few prospective comparative studies of accuracy between them, and this knowledge is still poorly investigated [20, 21]. The rationale of this study was to analyze the incidence, precocity, profile and the outcome impact of PPCs in patients who underwent AS and were admitted in a PICU (polyvalent intensive care unit) in order to find strategies that minimize their mortality.

\section{Methods}

Study patients were included from a universe of medical and surgical patients hospitalized in PICU of Hospital Garcia de Orta, Almada, Portugal, from January to December 2017. Sixty patients who were submitted to an urgent or elective AS and developed PPCs in the postoperative period leading to severe ARF despite the need for MV were retrospectively analyzed. The admission criteria in PICU were the surgical complexity level 4 and 5 according to L. R.
Pasternak classification (meaning highly invasive procedure, duration of surgery and intraoperative complications with usual postoperative PICU stay with invasive monitoring) and severity criteria (Table 1) of the patient [22]. All patients received standard clinical care and no researchrelated intervention was introduced. An experienced chest physician assessed the postoperative respiratory status of all patients. We collected data on the occurrence ( $\leq 48 \mathrm{~h}$ and $>$ $48 \mathrm{~h}$ ) of symptomatic and clinically significant PPCs using clinical, laboratory, and radiology data. We evaluated perioperative risk factors associated with PPCs, namely age and gender, body mass index (BMI), previous history of chronic obstructive pulmonary disease (COPD), serum albumin, type of anesthesia (general versus spinal anesthesia), type of surgery (laparotomy versus laparoscopy), use of NMBD during perioperative period, incision type, surgical intervention time and surgical procedure in urgent or elective context. PPCs have been defined according to EPCO and were diagnosed by clinical and radiological examinations and arterial blood gases (ABG), examined using the ABL 555 analyzer (Radiometer, Copenhagen, Denmark). Using clinical records, the risk of PPC was retrospectively estimated according to ASA PS and ARISCAT scores, and this data was compared with the real incidence. Right after surgery and $48 \mathrm{~h}$ after AS, pulmonary examinations of patients were repeated and when PPCs were present the following classifications were registered:

1. Atelectasis (by thoracic ultrasound, CT scan and/or $\mathrm{x}$-ray evidence of the collapse of the alveoli, lung opacification with the shift of the mediastinum, hilum, or hemidiaphragm toward the affected area, and compensatory over inflation in the adjacent non-atelectatic lung);

2. Bronchospasm (newly detected expiratory wheezing treated with bronchodilators), pleural effusion (chest radiograph demonstrating; blunting of the costophrenic angle, evidence of displacement of adjacent anatomical

Table 1 Severity criteria on admission, PICU Length of stay and mortality of patients undergoing AS

\begin{tabular}{|c|c|}
\hline Admitted patients & 60 cases \\
\hline $\begin{array}{l}\text { PICU hospitalization time in days } \\
\text { (median, min-max) } \\
\text { APACHE II (mean } \pm \text { standard deviation) } \\
\text { SAPS II (mean } \pm \text { standard deviation) }\end{array}$ & $\begin{array}{l}6.31 \text { days }[0.8-21] \\
22.8 \pm 8.1 \text { points } \\
50.7 \pm 17.9 \text { points }\end{array}$ \\
\hline PICU Mortality rate (n, \%) & 21.7\% (13 patients) \\
\hline Hospital mortality rate (n, \%) & 36.7\% (22 patients) \\
\hline SMR for SAPS II (median, min-max) & 0.68 points $[0.53-0.74]$ \\
\hline Readmission rate < 48 h (\%) & $0.9 \%$ \\
\hline $\begin{array}{l}\text { VAP, number of episodes/1000 days } \\
\text { of IT (median, min-max) }\end{array}$ & $8.7[7.1-10.3]$ \\
\hline
\end{tabular}


structures, or (in supine position) a hazy opacity in one hemithorax with preserved vascular shadows);

3. Pneumothorax (a collection of air in the pleural space - an area with no vascular bed surrounding the visceral pleura);

4. Acute Respiratory Distress Syndrome (ARDS) diagnosed by criteria of Berlin definition 2012 [23];

5. Pulmonary emboli (diagnosed if a patient had suggestive clinical findings, blood gas abnormality, consistent image of a pulmonary embolism on computed tomography with intravenous contrast);

6. Pneumonia (diagnosed if a patient had clinical, laboratory and/or radiological evidence of consolidation or infiltration not present in the preoperative chest roentgenograms), with or without positive cultures;

7. Tracheobronchitis (diagnosed if the patient had clinical, laboratory and no radiological evidence of consolidation or infiltration in chest roentgenograms);

8. Aspiration pneumonitis (acute lung injury after the inhalation of regurgitated gastric contents);

9. ARF (postoperative arterial oxygen pressure $(\mathrm{PaO} 2)<60 \mathrm{mmHg}$ on room air, a ratio of $\mathrm{PaO} 2$ to inspired oxygen fraction $(\mathrm{FiO} 2)<300$, or arterial oxygen saturation $(\mathrm{SaO} 2)<90 \%$ and requiring oxygen therapy).

10. Patient optimization means control of chronic diseases and kinesiotherapy.

11. The term "prehabilitation", is a combination of the words "pre- "and "rehabilitation". Prehabilitation concerns a combination of preparational and postprocedure measures to improve the outcome of a planned procedure, such as major surgery. Prehabilitation programs are used to improve postoperative outcomes. These programs before surgery, involve preoperative lifestyle changes, such as nutritional supplementation, exercise, stress reduction, and smoking cessation. Therefore structured and sustained exercise over a period of few weeks leads to improved cardiovascular, respiratory, and muscular conditioning.

The incidence of PPCs, the profile and the postoperative mortality associated defined as death within 30 days of surgery were also evaluated.

All statistical analyses were performed with R Statistical software (version 3.6.0). Continuous variables were described using median and range or mean \pm standard deviation, and categorical variables were expressed as frequencies or percentages. Student's t-tests were used for comparing continuous variables, and chi-squared tests or Fisher's exact tests were used for comparing categorical data. A $p$-value of $<0.05$ was considered to be statistically significant. Logistic regression was performed to determine which perioperative risk factors were associated with the development of PPCs.

The Ethics Committee of Hospital Garcia de Orta approved the study protocol.

\section{Results}

In our sample, 45 (75\%) males and 15 (25\%) females, with a median (min-max) age of 64.5 years $(47-81)$ were submitted to urgent or elective abdominal surgery. Severity criteria on admission, PICU Length of stay and mortality of patients undergoing AS are shown in Table 1. Thirty six patients underwent emergency surgery and the remaining 24, elective surgery (Table 2).

\section{PPC group description}

Thirty-six patients (60\%) developed PPCs within $48 \mathrm{~h}$, from which $29(80.6 \%)$ were male. The median (min$\max )$ age was $65(54-81)$ years. Twelve patients $(20 \%)$ developed additional PPCs related with invasive ventilation side effects after $48 \mathrm{~h}$. Twenty-four $(40 \%)$ only developed PPCs after $48 \mathrm{~h}$. From these, 16 (66.7\%) were male. The median (min-max) age was 64.5 (49-81) years. We did not find significant differences in the median age of the two groups $(p=0.2)$.

Pneumonia was the most frequent PPC in the sample (PPCs $\leq 48 \mathrm{~h}$ and $>48 \mathrm{~h}$; Fig. 1). Regarding the patients who developed additional PPCs after $48 \mathrm{~h}$, the complications were 7 tracheobronchitis, 6 bronchospasms, 5 atelectasis, 5 ARDS, 3 pleural effusion and 1 pneumothorax.

In the emergency setting, peritonitis had the highest rate of PPCs. The group of electively treated patients who developed PPCs was mostly carriers of digestive malignancies (Table 2).

\section{Perioperative relevant risk factor for the development of PPCs}

Regarding the preoperative variables and the risk of PPCs, we verified that the knowledge of ASA score 4 before surgery associated with measures to optimize performance status revealed to be a PPC protection factor $(\mathrm{OR}=0.04 ; 95 \% \mathrm{CI}: 0.01-0.28)$. Patients with a high risk ARISCAT score also showed a reduced risk of developing PPCs after $48 \mathrm{~h}(\mathrm{OR}=0.17$; 95\%CI: 0.03-0.88). In this group of patients, preoperative performance status optimization and/or early diagnosis of pulmonary impairment reflected a reduced risk of PCCs, as we mentioned before. A significantly lower risk of PCCs was also observed for patients undergoing a median surgical incision, in the first $48 \mathrm{~h}(\mathrm{OR}=0.22$; $95 \% \mathrm{CI}$ : $0.06-0.79)$, and for patients with more time-consuming surgeries, after $48 \mathrm{~h}(\mathrm{OR}=0.29$; 95\%CI: 0.09-0.90). In contrast, patients with pre-operative abnormal arterial blood gases prior to surgery $(\mathrm{OR}=3.50 ; 95 \% \mathrm{CI}$ : $1.14-10.74)$ or who required NMBD several times intraoperatively had a higher risk of PPCs in the first $48 \mathrm{~h}(\mathrm{OR}=18.40$; 95\%CI: 2.24-151.35). High BMI was significantly associated with the occurrence of PPCs after $48 \mathrm{~h}(\mathrm{OR}=15.40$; 95\%CI: 1.47-160.97) (Table 3). 
Table 2 AS etiology in patients with PPCS

\begin{tabular}{|c|c|c|c|c|c|}
\hline \multirow[t]{2}{*}{ Etiology } & \multirow{2}{*}{$\begin{array}{l}\text { Patients } \\
(n, \%)\end{array}$} & \multicolumn{2}{|c|}{ Emergency surgery $(\mathrm{n}, \%)$} & \multicolumn{2}{|c|}{ Elective surgery (n, \%) } \\
\hline & & $\leq 48 \mathrm{~h}$ & $>48 \mathrm{~h}$ & $\leq 48 \mathrm{~h}$ & $>48 \mathrm{~h}$ \\
\hline Peritonitis & $11(18.3)$ & $9(15.0)$ & $2(3.3)$ & - & - \\
\hline Colorectal cancer & $9(15.0)$ & - & $2(3.3)$ & $7(11.7)$ & - \\
\hline Mesenteric ischemia & $8(13.3)$ & $1(1.7)$ & $7(11.7)$ & - & - \\
\hline Cholangiocarcinoma & $5(8.3)$ & - & - & $3(5.0)$ & $2(3.3)$ \\
\hline Bowel obstruction & $4(6.7)$ & $3(5.0)$ & $1(1.7)$ & - & - \\
\hline Abdominal trauma & $3(5.0)$ & $2(3.3)$ & $1(1.7)$ & - & - \\
\hline Acute Pancreatitis & $3(5.0)$ & - & $3(5.0)$ & - & - \\
\hline Gastric cancer & $5(8.3)$ & - & - & $4(6.7)$ & $1(1.7)$ \\
\hline Esophageal cancer & $5(8.3)$ & - & - & $5(8.3)$ & - \\
\hline Cholecystitis & $5(8.3)$ & $2(3.3)$ & $3(5.0)$ & - & - \\
\hline Diverticulitis & $1(1.7)$ & - & - & - & $1(1.7)$ \\
\hline Abdominal aortic aneurysm & $1(1.7)$ & - & - & - & $1(1.7)$ \\
\hline
\end{tabular}

No significant differences in APACHE and SAPS scores were found between the patients that developed PPCs in the first $48 \mathrm{~h}$ and the group of patients that only developed PPCs after $48 \mathrm{~h}$ (APACHE: $p=0.829$; SAPS: $p=0.378)$ (Table 4).

\section{Mechanical ventilation and mortality relevant factors}

In our sample, 48 patients developed ARF and needed mechanical ventilation, 23 (47.9\%) patients within $24 \mathrm{~h}$ and $25(52.1 \%)$ after $24 \mathrm{~h}$. In only 1 of these patients, a noninvasive method was the first attempt. Patients with COPD or asthma history and optimized ASA score 4 were less ventilated. All cases with elevated lactate $12 \mathrm{~h}$ after surgery developed PPCs and required ventilation. Patients with proven respiratory infection required ventilation within $24 \mathrm{~h}$.

Thirty-day mortality of patients with PPCs was analyzed and its association with the APACHE II and SAPS II scores were assessed. No significant association was found between these scores and 30-day mortality. Mortality was lower in optimized patients (ASA 4: $p=0.04$ ). Patients with albumin deficiency before surgery had major and significant mortality in the first 30 days after surgery $(p=0.01)$.

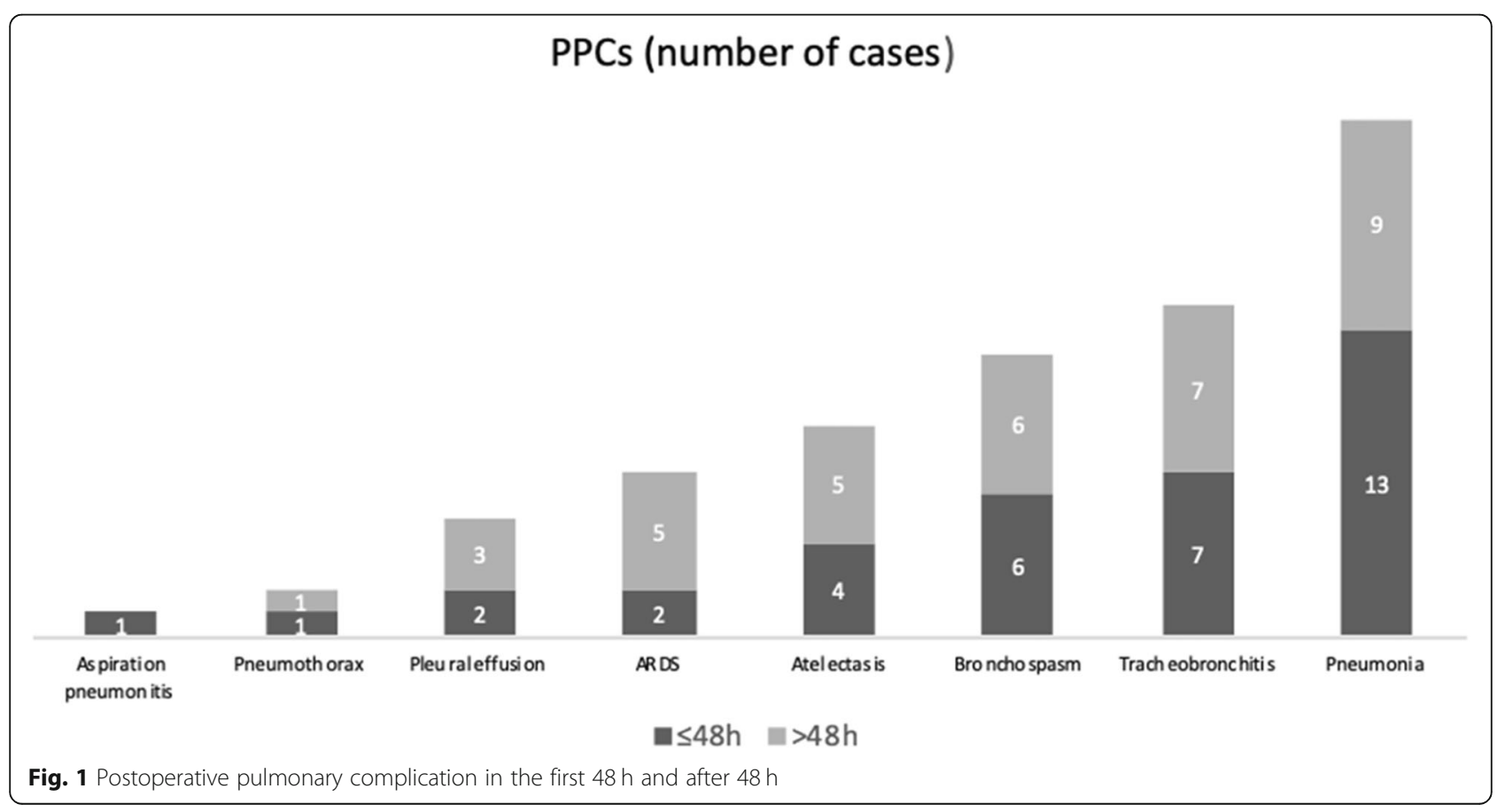


Table 3 Potential perioperative risk factors and PPCS, Mechanical Ventilation and 30-day mortality

\begin{tabular}{|c|c|c|c|c|c|}
\hline \multirow[t]{3}{*}{ Variable } & \multirow[t]{3}{*}{$\mathrm{n}$} & \multicolumn{2}{|c|}{$\begin{array}{l}\text { PPC } \\
\text { (Postoperative Pulmonary Complications) }\end{array}$} & \multirow{3}{*}{$\begin{array}{l}\text { Mechanical Ventilation } \\
\text { OR }(95 \% \text { C.I. })^{a}\end{array}$} & \multirow{3}{*}{$\begin{array}{l}\text { 30-Day Mortality } \\
\text { OR }(95 \% \text { C.I. })^{\text {a }}\end{array}$} \\
\hline & & \multirow{2}{*}{$\begin{array}{l}\leq 48 \mathrm{~h} \\
\text { OR }(95 \% \text { C.I. })^{a}\end{array}$} & \multirow{2}{*}{$\begin{array}{l}>48 \mathrm{~h} \\
\text { OR }(95 \% \text { C.I. })^{\mathrm{a}}\end{array}$} & & \\
\hline & & & & & \\
\hline \multicolumn{6}{|l|}{ Sex } \\
\hline M & 45 & 1 & 1 & 1 & 1 \\
\hline $\mathrm{F}$ & 15 & $0.48(0.15-1.58)$ & $3.50(0.87-14.11)$ & $0.59(0.15-2.35)$ & $2.31(0.62-8.64)$ \\
\hline \multicolumn{6}{|l|}{ NMBD } \\
\hline No & 43 & 1 & 1 & 1 & 1 \\
\hline Yes & 17 & $18.40(2.24-151.35)$ & $0.67(0.21-2.08)$ & $* *$ & $2.81(0.78-10.12)$ \\
\hline Age & 60 & $1.05(0.98-1.13)$ & $0.95(0.89-1.03)$ & $1.01(0.93-1.10)$ & $1.05(0.97-1.15)$ \\
\hline \multicolumn{6}{|l|}{ ASA } \\
\hline 1 & 18 & 1 & 1 & 1 & 1 \\
\hline 2 & 17 & $0.37(0.07-1.80)$ & $0.56(0.14-2.21)$ & $0.94(0.05-16.35)$ & $1.09(0.27-4.41)$ \\
\hline 3 & 13 & $0.32(0.06-1.70)$ & $0.31(0.07-1.38)$ & $0.13(0.01-1.37)$ & $0.17(0.02-1.60)$ \\
\hline 4 & 12 & $0.04(0.01-0.28)$ & $2.50(0.41-15.23)$ & $0.06(0.01-0.59)$ & $* *$ \\
\hline \multicolumn{6}{|l|}{ ARISCAT } \\
\hline Low risk $<26$ & 14 & 1 & 1 & 1 & 1 \\
\hline Intermediate Risk 26-44 & 16 & $1.65(0.37-7.37)$ & $0.21(0.04-1.29)$ & $0.72(0.10-5.09)$ & $1.50(0.32-6.99)$ \\
\hline High risk $>45$ & 30 & $0.98(0.27-3.53)$ & $0.17(0.03-0.88)$ & $0.55(0.10-3.06)$ & $0.28(0.05-1.47)$ \\
\hline \multicolumn{6}{|l|}{ Respiratory Infection } \\
\hline No & 50 & 1 & 1 & 1 & 1 \\
\hline Yes & 10 & $1.00(0.25-4.00)$ & $1.69(0.39-7.31)$ & $2.54(0.29-22.27)$ & $1.71(0.38-7.84)$ \\
\hline \multicolumn{6}{|l|}{ Anemia } \\
\hline No & 30 & 1 & 1 & 1 & 1 \\
\hline Yes & 30 & $0.76(0.27-2.13)$ & $2.33(0.81-6.73)$ & $1.00(0.28-3.54)$ & $1.22(0.36-4.17)$ \\
\hline \multicolumn{6}{|l|}{ Incision Type } \\
\hline Bilateral subcostal & 21 & 1 & 1 & 1 & 1 \\
\hline Median & 39 & $0.22(0.06-0.79)$ & $4.14(1.34-12.72)$ & $0.13(0.02-1.07)$ & $0.55(0.16-1.91)$ \\
\hline \multicolumn{6}{|l|}{ LPT vs. LPC } \\
\hline LPC (Laparoscopy) & 19 & 1 & 1 & 1 & 1 \\
\hline LPT (Laparotomy) & 41 & $1.14(0.38-3.43)$ & $1.14(0.38-3.43)$ & $1.73(0.47-6.40)$ & $0.45(0.13-1.58)$ \\
\hline \multicolumn{6}{|l|}{ Surgery Duration } \\
\hline$<180 \min$ & 42 & 1 & 1 & 1 & 1 \\
\hline$>180 \min$ & 18 & $3.18(0.90-11.28)$ & $0.29(0.09-0.90)$ & $2.50(0.49-12.79)$ & $2.50(0.70-8.92)$ \\
\hline \multicolumn{6}{|l|}{ Smokers } \\
\hline No & 35 & 1 & 1 & 1 & 1 \\
\hline Yes & 25 & $1.33(0.46-3.83)$ & $0.75(0.26-2.14)$ & $1.00(0.28-3.61)$ & $0.55(0.15-2.04)$ \\
\hline \multicolumn{6}{|l|}{ BMl } \\
\hline$<18$ & 12 & 1 & 1 & 1 & 1 \\
\hline $18-25$ & 20 & $0.78(0.15-3.93)$ & $1.40(0.33-5.93)$ & $* *$ & $0.75(0.14-4.13)$ \\
\hline $25-30$ & 16 & $0.56(0.11-2.90)$ & $2.33(0.51-10.78)$ & $* *$ & $1.36(0.25-7.32)$ \\
\hline $30-35$ & 12 & $0.11(0.02-0.71)$ & $15.40(1.47-160.97)$ & $* *$ & $0.27(0.02-3.09)$ \\
\hline \multicolumn{6}{|l|}{ COPD/Asthma History } \\
\hline No & 42 & 1 & 1 & 1 & 1 \\
\hline Yes & 18 & $0.56(0.18-1.70)$ & $2.15(0.65-7.11)$ & $0.21(0.06-0.80)$ & $1.63(0.45-5.92)$ \\
\hline
\end{tabular}


Table 3 Potential perioperative risk factors and PPCS, Mechanical Ventilation and 30-day mortality (Continued)

\begin{tabular}{|c|c|c|c|c|c|}
\hline \multirow[t]{3}{*}{ Variable } & \multirow[t]{3}{*}{$\mathrm{n}$} & \multicolumn{2}{|c|}{$\begin{array}{l}\text { PPC } \\
\text { (Postoperative Pulmonary Complications) }\end{array}$} & \multirow{3}{*}{$\begin{array}{l}\text { Mechanical Ventilation } \\
\text { OR }(95 \% \text { C.I. })^{a}\end{array}$} & \multirow{3}{*}{$\begin{array}{l}\text { 30-Day Mortality } \\
\text { OR }(95 \% \text { C.I. })^{\mathrm{a}}\end{array}$} \\
\hline & & \multirow{2}{*}{$\begin{array}{l}\leq 48 \mathrm{~h} \\
\text { OR }(95 \% \text { C.I. })^{\mathrm{a}}\end{array}$} & \multirow{2}{*}{$\begin{array}{l}>48 \mathrm{~h} \\
\text { OR }(95 \% \text { C.I. })^{\mathrm{a}}\end{array}$} & & \\
\hline & & & & & \\
\hline \multicolumn{6}{|l|}{ POSA } \\
\hline$\leq 35 \mathrm{~g} / \mathrm{L}$ & 8 & $5.55(0.64-48.41)$ & $0.63(0.14-2.79)$ & $1.88(0.21-16.92)$ & $19.29(3.23-115.22)$ \\
\hline$>35 \mathrm{~g} / \mathrm{l}$ & 52 & 1 & 1 & 1 & 1 \\
\hline \multicolumn{6}{|l|}{ Lactate } \\
\hline$<4 \mathrm{mmol} / \mathrm{l}$ & 14 & 1 & 1 & 1 & 1 \\
\hline$>4 \mathrm{mmol} / \mathrm{l}$ & 46 & $0.52(0.14-1.90)$ & $1.17(0.35-3.92)$ & ** & $0.38(0.10-1.44)$ \\
\hline \multicolumn{6}{|c|}{ PREOP Abnormal Arterial blood gases } \\
\hline No & 20 & 1 & 1 & 1 & 1 \\
\hline Yes & 40 & $3.50(1.14-10.74)$ & $0.16(0.04-0.63)$ & $1.57(0.43-5.77)$ & $0.49(0.14-1.74)$ \\
\hline \multicolumn{6}{|c|}{$\mathrm{Pa} 02 \leq 50 \geq 60$ Moderate - Severe ARF } \\
\hline No & 25 & 1 & 1 & 1 & 1 \\
\hline Yes & 35 & $2.36(0.82-6.83)$ & $0.41(0.14-1.23)$ & $1.53(0.43-5.44)$ & $1.82(0.49-6.74)$ \\
\hline \multicolumn{6}{|l|}{$\mathrm{Pa02} / \mathrm{FiO} 2$} \\
\hline$<100$ & 21 & $0.83(0.28-2.45)$ & $1.13(0.38-3.35)$ & $1.80(0.43-7.53)$ & $* *$ \\
\hline $101-300$ & 39 & 1 & 1 & 1 & 1 \\
\hline \multicolumn{6}{|c|}{ PREOP Abnormal Chest radiography } \\
\hline No & 36 & 1 & 1 & 1 & 1 \\
\hline Yes & 24 & $3.00(0.97-9.30)$ & $0.37(0.13-1.09)$ & $4.23(0.84-21.40)$ & $2.06(0.59-7.13)$ \\
\hline
\end{tabular}

ASA PS American Society of Anesthesiologists physical status, $B M I$ body mass index, $C O P D$ Chronic Obstructive Pulmonary Disease, FiO ${ }_{2}$ Inspiratory oxygen fraction, $L P C$ Laparoscopy, LPT Laparotomy, NMBD Neuromuscular blocking drugs, $\mathrm{PaO}_{2}$ arterial oxygen pressure, $P R E O P$ preoperative period, $P O S A$ preoperative serum albumin. a Unadjusted (Univariable Model); ${ }^{* *}$ No cases in at least one of the groups; Bold - significant values.

\section{Discussion}

To the best of our knowledge, this is the first study that evaluates the profile of PPCs in a population submitted to abdominal surgery in Portugal. We observed that PPCs occur within $48 \mathrm{~h}$ in $60 \%$ of abdominal surgical patients that need ICU care in the immediate postoperative period. Patients operated in an emergency setting for peritonitis had the highest rate of PPCs. In the elective setting, patients who were operated due to a digestive cancer were more prone to a PPC. Forty-eight patients developed ARF. In accordance with our results, the report of Serejo et al. [24] recorded a $28.2 \%$ incidence of pulmonary complications, in patients undergoing emergency abdominal surgery. Kumar et al. studied one hundred and fifty patients who underwent abdominal surgery, and of these, $16 \%$ developed PPCs and the highest incidence occurred in the emergency surgery group too [25]. Verma et al. conducted a study of PPCs in patients of emergency abdominal surgeries and found that pre-operative abnormal chest $\mathrm{X}$-ray changes were 3 times more common in the PPCs group as compared to the control group without PPCs [26]. In our study, no significant association was observed between this variable and the occurrence of PPCs. On the other hand, regarding elective surgery, Yang and colleagues [6] confirmed this finding, reporting a higher incidence of PPCs in esophagectomy and other upper abdominal procedures as we found in our series.

We observed that patients with ASA score 4 and highrisk ARISCAT score before surgery had a lower risk of complications within the first $48 \mathrm{~h}$ and after $48 \mathrm{~h}$, respectively, as they were previously optimized. Low

Table 4 PPCs, 30-day mortality and Severity Indices

\begin{tabular}{lllll}
\hline Patients undergoing AS & Patients number (\%) & 30-day mortality & APACHE II (mean) & SAPS II (mean) \\
\hline OP & $60(100)$ & $21.7 \%$ & $22.8 \pm 8.1^{*}$ & $50.7 \pm 17.9^{*}$ \\
PPCS $\leq 48 \mathrm{~h}$ & $36(60)$ & $27.8 \%(10$ patients) & $23.0 \pm 6.5^{* *}$ & $49.0 \pm 17.3^{* *}$ \\
PPCS $>48 \mathrm{~h}$ & $24(40)$ & $12.5 \%(3$ patients $)$ & $22.5 \pm 10.2^{* *}$ & $53.2 \pm 18.9^{* *}$ \\
\hline
\end{tabular}

APACHE Acute Physiology, Age, Chronic Health Evaluation, AS abdominal surgery, OP operated patients, PPCs postoperative pulmonary complications, SAPS Simplified Acute Physiology Score; * (APACHE: $p=0.829$; SAPS: $p=0.378$ ). ${ }^{* *}$ statistically not significant 
albumin levels were found to be poor prognostic factor. It is important to underline that in cases of emergency surgery we cannot modify these risk factors. However, in elective surgery, even in digestive oncological diseases, we have time to optimize these patients. In this sense, there is evidence that prehabilitation programs reduced the risk of complications including respiratory ones [27] and such a prehabilitation program is being implemented in our Institutions.

High ARISCAT score, high BMI, pre-operative abnormal arterial blood gases, and albumin deficiency before surgery can be a surrogate marker for prehabilitation measures to improve their prevention. In several studies, the ARISCAT score has proved its efficacy in the identification of PPCs risk in the surgical population, including the population submitted to abdominal surgery. This score was already validated for the Portuguese population [28, 29].

We found that, in the first $48 \mathrm{~h}$ after ICU admission, the identification of lactate acidemia or pre-operative abnormal arterial blood gases plays an important role in therapeutic measures with a positive impact on the outcome of these patients. In the group that needed ventilation $24 \mathrm{~h}$ after surgery that had alterations in the arterial gasometry and that required neuromuscular blockade several times during surgery had an increased risk of pulmonary complications. Creagh-Brown et al. [30] evaluated the effect of the peak serum lactate, in the first 24 $\mathrm{h}$ of ICU admission after major gastrointestinal surgery, in a large cohort of patients from nearly 250 hospitals in the United Kingdom. In that study, they found an increased in-hospital mortality associated with elevated lactate levels, with no difference between elective and emergency surgery. Veličković et al. showed that lactate levels measured at $12 \mathrm{~h}$ after the operation had the highest predictive ability for diagnosis of overall postoperative complications including PPCs and the postoperative in-hospital mortality [31]. Therefore, lactates should be monitored in the immediate postoperative because they help to identify the risk of PPCs.

In our series, patients who required NMBD several times intraoperatively developed a higher rate of PPCs in the first $48 \mathrm{~h}$. Recent studies evaluating the use of neuromuscular blocking agents and postoperative complications have demonstrated growing evidence for a clear relationship between the use of these agents and PPCs complications [32].

It is necessary to underline that the need for invasive mechanical ventilation was understood by us as the extreme consequence of a PPC. As a respiratory support technique it is not, by itself, obviously therapeutic, and may be associated with several complications, namely mechanical ventilation lung injury, usually manifested in the form of barotrauma, volutrauma, atelectrauma, biotrauma and more recently ergotrauma, globally inserted in the new energy concept of mechanical power, which is now thought to be the basis of mechanical ventilation lung injury [33, 34]. The severity of mechanical ventilation lung injury is partly dependent on the duration of the injury, which is why the safety and efficacy binomial are two important factors. However, in our series ventilation was not correlated with 30-day mortality.

Fernandez-Bustamante et al. [7] in a recent report of 1202 patients undergoing non-cardiothoracic surgery under general anesthesia, patients with at least one pulmonary complication had higher rates of mortality, ICU admission, and length of stay, and all patients were ASA PS class 3 or greater. In our series 25 patients (41.7\%) were classified ASA PS classes 3 and 4, who were responsible for 10 (16.7\%) of the PPCs before $48 \mathrm{~h}$ and 15 (25\%) of the PPCs after $48 \mathrm{~h}$. As mentioned before, patients with ASA score 4 had less PPCs in the first $48 \mathrm{~h}$ since they received preoperative optimization.

The 30-days postoperative mortality was higher in PPCs developed within $48 \mathrm{~h}$ (27.8\%), therefore these complications revealed a high lethality rate. Patel et al. also showed that 30-day mortality was higher in patients undergoing abdominal surgery with PPCs [4]. Patients with albumin deficiency prior to surgery had a higher risk of death in the first 30 days after surgery. Lunardi A et al. showed that malnutrition is associated with weakness of the expiratory muscles, decreased chest wall expansion and increased incidence of pulmonary complications in patients undergoing elective upper abdominal surgery [35].

This study has limitations regarding the size of the sample. On the other hand, the fact that it includes only patients who required intensive care after abdominal surgery makes it more homogeneous. Taking our results together, we consider that it is necessary to define variables that predict lung complications in the postoperative period and to establish strategies for the mitigation of PPCs after surgery.

Duarte and Machado reviewed the epidemiology, risk factors and prevention of PPCs and concluded that the clinical and social consequences of PPCs are huge and that prevention of its high incidence continues to be a growing challenge focusing on the importance of preventive strategies, which should be systematically applied in order to achieve better results [36].

Major AS is a great stressor to patients and causes large physiological changes, leads to tissue trauma, immobility, psychological distress and reduced quality of life [37, 38].

Physical exercise prehabilitation has been proposed to improve postoperative outcomes in patients undergoing major AS. Several studies have been published in the literature investigating the effect of preoperative exercise training compared with standard care on postoperative outcomes in major AS concluding that the effect is beneficial [39].

The improvement of physical capacity through prehabilitation may facilitate better recovery after surgery and 
the current evidence is that prehabilitation protocols and optimization of preoperative care, in particular, respiratory function, may reduce PPCs incidence and mortality [40-42]. In this sense, it is important to study more comprehensive preoperative risk scores such as PPossum and ACS NSIQ Risk Calculator to better identify risk patients [43-48].

\section{Conclusions}

PPCs after abdominal surgery are still a major problem since they have profound effects on outcomes. Our results suggest that programs before surgery, involve preoperative lifestyle changes, such as nutritional supplementation, exercise, stress reduction, and smoking cessation, recently defined as prehabilitation, was an effective strategy in mitigating postoperative complications by decreasing mortality.

\section{Abbreviations}

ABG: Arterial Blood Gases; ARDS: Acute Respiratory Distress Syndrome; ARF: Acute Respiratory Failure; ARISCAT: Assess Respiratory Risk in Surgical Patients in Catalonia; AS: Abdominal Surgery; ASA PS: Anesthesiologists Physical Status; BMI: Body Mass Index; COPD: Chronic Obstructive Pulmonary Disease; EPCO: European Perioperative Clinical Outcome; MV: Mechanical Ventilation; NMBD: Neuromuscular Blocking Drugs; PICU: Polyvalent Intensive Care Unit; POCs: Postoperative Complications; PPCs: Postoperative Pulmonary Complications

\section{Acknowledgments}

Group of Experimental and Therapeutic Pathology, Department of Surgical Oncology and Department of Epidemiology of the Portuguese Oncology Institute of Porto FG, EPE (IPO-Porto) and the Science and Technology Foundation (FCT), for the possibility of assessing a large series of digestive surgical oncology patients, with the aim of validating a predictive risk score for the development of POCs.

\section{Authors' contributions}

AF and LLS were responsible for the primary conception and design of the article with input from co-authors. Initial drafts of the article were prepared by LLS, AF, JR, LA, and CSS. Additions, modifications, and revisions critical for the important intellectual content of the article were performed by LLS, CC, RSC, CSL, PMC, PL, SL, PM, including final approval of the version to be published. All authors read and approved the final manuscript.

\section{Funding}

FCT project IPOscore (DSAIPA/DS/0042/2018).

\section{Ethics approval and consent to participate}

The ethics committee of the Hospital Garcia de Orta approved the present study. The authors involved agreed to integrate the research.

\section{Consent for publication}

The authors gave their agreement for the publication of the manuscript.

\section{Competing interests}

There is no competing interests or financial interest amongst authors to disclose.

\section{Author details}

${ }^{1}$ Experimental Pathology and Therapeutics Group, Instituto Português de Oncologia, Porto, Portugal. ${ }^{2}$ Polyvalent Intensive Care Unit of Intensive Medicine Service, Hospital Garcia de Orta, E.P.E, Almada, Portugal. ${ }^{3}$ Cancer Epidemiology Group, IPO Porto Research Center (CI-IPOP), Instituto Português de Oncologia, Porto, Portugal. ${ }^{4}$ General Surgery Service, Hospital Garcia de Orta, E.P.E, Portugal and Faculdade de Medicina da Universidade de Lisboa, Almada, Portugal. ${ }^{5}$ Polyvalent Intensive Care Unit, Hospital Santo Espírito ilha Terceira, E.P.R, Angra do Heroísmo, Açores, Portugal. ${ }^{6}$ Surgical
Oncology Department of Portuguese Instituto Português de Oncologia,

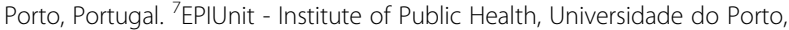
Porto, Portugal. ${ }^{8}$ IDMEC, Instituto Superior Técnico, Universidade de Lisboa, Lisbon, Portugal. ${ }^{9}$ REQUIMTE/LAQV, Department of Chemistry, Faculty of Science and Technology, Universidade Nova de Lisboa, Caparica, Portugal. ${ }^{10}$ Biomedical Sciences Institute Abel Salazar, Universidade do Porto, Porto, Portugal.

Received: 3 July 2019 Accepted: 21 November 2019

Published online: 03 December 2019

\section{References}

1. Weiser TG, Regenbogen SE, Thompson KD, Haynes AB, Lipsitz SR, Berry WR, Gawande AA. An estimation of the global volume of surgery: a modeling strategy based on available data. Lancet. 2008;372(9633):139-44.

2. Kazaure HS, Roman SA, Sosa JA. Association of Postdischarge Complications with Reoperation and Mortality in general surgery. Arch Surg. 2012 Nov; 147(11):1000-7.

3. Jammer I, Wickboldt N, Sander M, Smith A, Schultz MJ, Pelosi P, Leva B, Rhodes A, Hoeft A, Walder B, Chew MS, Pearse RM, European Society of Anaesthesiology (ESA) and the European Society of Intensive Care Medicine (ESICM). Standards for definitions and use of outcome measures for clinical effectiveness research in perioperative medicine: European Perioperative Clinical Outcome (EPCO) definitions. A statement from the ESA-ESICM joint taskforce on perioperative outcome measures. Eur J Anaesthesiol. 2015; 32(2):88-105.

4. Patel K, Hadian F, Ali A, Broadley G, Evans K, Horder C, Johnstone M, Langlands F, Matthews J, Narayan P, Rallon P, Roberts C, Shah S, Vohra R. Postoperative pulmonary complications following major elective abdominal surgery: a cohort study. Perioper Med (Lond). 2016;5:10.

5. Arozullah AM, Daley J, Henderson WG, Khuri SF. Multifactorial risk index for predicting postoperative respiratory failure in men after major noncardiac surgery. The National Veterans Administration Surgical Quality Improvement Program. Ann Surg. 2000;232(2):242-53.

6. Yang CK, Teng A, Lee DY, Rose K. Pulmonary complications after major abdominal surgery: National Surgical Quality Improvement Program analysis. J Surg Res. 2015:198(2):441-9.

7. Fernandez-Bustamante A, Frendl G, Sprung J, Kor DJ, Subramaniam B, Martinez Ruiz R, Lee JW, Henderson WG, Moss A, Mehdiratta N, Colwell MM, Bartels K, Kolodzie K, Giquel J, Vidal Melo MF. Postoperative pulmonary complications, early mortality, and hospital stay following noncardiothoracic surgery: a multicenter study by the perioperative research network investigators. JAMA Surg. 2017:152(2):157-66.

8. Rehder K. Anesthesia and the respiratory system. Can Anaesth Soc J. 1979; 26(6):451-62.

9. Zambouri A. Preoperative evaluation and preparation for anesthesia and surgery. Hippokratia. 2007;1:13-21.

10. Miskovic A, Lumb AB. Postoperative pulmonary complications. $\mathrm{Br}$ J Anaesth. 2017;118(3):317-34.

11. O'Donohue WJ Jr. Postoperative pulmonary complications. When are preventive and therapeutic measures necessary? Postgrad Med. 1992;91(3): 167-70 173-5.

12. Smetana GW, Lawrence VA, Cornell JE. American College of Physicians. Preoperative pulmonary risk stratification for noncardiothoracic surgery: a systematic review for the American College of Physicians. Ann Intern Med. 2006;144(8):581-95.

13. Canet J, Mazo V. Postoperative pulmonary complications. Minerva Anestesiol. 2010;76(2):138-43.

14. Barisione G, Rovida S, Gazzaniga GM, Fontana L. Upper abdominal surgery: do a lung function test exist to predict early severe postoperative respiratory complications? Eur Respir J. 1997;10(6):1301-8.

15. Kocabas A, Kara K, Ozgur G, Sonmez H, Burgut R. Value of preoperative spirometry to predict postoperative pulmonary complications. Respir Med. 1996;90(1):25-33.

16. Brooks Brunn JA. Predictors of postoperative pulmonary complications following abdominal surgery. Chest. 1997;111:564-71.

17. Ford GT, Rosenal TW, Clerque F, Whitelaw WA. Respiratory physiology in upper abdominal surgery. Clin Chest Med. 1993;14:237-52.

18. Gass GD, Olsen GN. Preoperative pulmonary function testing to predict postoperative morbidity and mortality. Chest. 1986;89:127-35. 
19. Kupeli E, Er Dedekarginoglu B, Ulubay G, Oner Eyuboglu F, Haberal M. American Society of Anesthesiologists Classification Versus ARISCAT Risk Index: Predicting Pulmonary Complications Following Renal Transplant. Exp Clin Transplant 2017; Suppl 1: 208-213.

20. Ghaferi AA, Birkmeyer JD, Dimick JB. Variation in hospital mortality associated with inpatient surgery. N Engl J Med. 2009;361(14):1368-75.

21. Pearse RM, Moreno RP, Bauer P, Pelosi P, Metnitz P, Spies C, Vallet B, Vincent $J$, Hoeft A. Rhodes A; European Surgical Outcomes Study (EuSOS) group for the Trials groups of the European Society of Intensive Care Medicine and the European Society of Anaesthesiology. Mortality after surgery in Europe: a 7-day cohort study. Lancet. 2012;380(9847):1059-65.

22. Pasternak R. Screening patients- strategies and studies. In: McGoldrick K, editor. Ambulatory Anesthesiology- A problem-oriented approach. Philadelphia: Williams and Wilkins; 1995

23. ARDS Definition Task Force, Ranieri VM, Rubenfeld GD, Thompson BT, Ferguson ND, Caldwell E, Fan E, Camporota L, Slutsky AS. Acute respiratory distress syndrome: the Berlin Definition. JAMA. 2012;307(23):2526-33.

24. Serejo LG, da Silva-Júnior FP, Bastos JP, de Bruin GS, Mota RM, de Bruin PF. Risk factors for pulmonary complications after emergency abdominal surgery. Respir Med. 2007 Apr;101(4):808-13.

25. Kumar L, Satheesan KN, Rajan S, Vasu BK, Paul J. Predictors and outcomes of postoperative pulmonary complications following abdominal surgery in a south Indian population. Anesth Essays Res. 2018;12(1):199-205.

26. Verma S, Bhardwaj A, Patil SM. Study of postoperative pulmonary complications in patients of emergency abdominal surgeries. Int Surg J. 2018;5(9):3057-65.

27. Bolshinsky V, Li MH, Ismail H, Burbury K, Riedel B, Heriot A. Multimodal Prehabilitation programs as a bundle of Care in Gastrointestinal Cancer Surgery: a Systematic Review. Dis Colon Rectum. 2018;61(1):124-38.

28. Brueckmann B, Villa-Uribe JL, Bateman BT, Grosse-Sundrup M, Hess DR Schlett CL. Matthias Eikermann. Development and validation of a score for prediction of postoperative respiratory complications. Anesthesiology. 2013; 118:1276.

29. Mazo V, Sabaté S, Canet J, Gallart L, de Abreu MG, Belda J, Langeron O, Hoeft A, Pelosi P. Prospective external validation of a predictive score for postoperative pulmonary complications. Anesthesiology. 2014;121(2):219-31.

30. Creagh-Brown BC, De Silva AP, Ferrando-Vivas P, Harrison DA. Relationship between peak lactate and patient outcome following high-risk gastrointestinal surgery: influence of the nature of their surgery: elective versus emergency. Crit Care Med. 2016;44:918-25.

31. Veličković J, Palibrk I, Miličić B, Veličković D, Jovanović B, Rakić G, Petrović M, Bumbaširević $V$. The association of early postoperative lactate levels with morbidity after elective major abdominal surgery. Bosn J Basic Med Sci. 2019;19(1):72-80

32. Mathews L, Ehrenfeld JM. Neuromuscular Blocking Drugs and Postoperative Pulmonary Complications. Curr Anesthesiol Rep. 8(2):157-60.

33. Nieman GF, Satalin J, Andrews P, Aiash H, Habashi NM, Gatto LA. Personalizing mechanical ventilation according to physiologic parameters to stabilize alveoli and minimize ventilator-induced lung injury (VILI). Inten Care Med Exper. 2017;5:8.

34. Gattinoni L, Marini JJ, Collino F, Maiolo G, Rapetti F, Tonetti T, Vasques F, Quintel M. The future of mechanical ventilation: lessons from the present and the past. Critical Care. 2017;21:183.

35. Lunardi AC, Miranda CS, Silva KM, Cecconello I, Carvalho CR. Weakness of expiratory muscles and pulmonary complications in malnourished patients undergoing upper abdominal surgery. Respirology. 2012;17:108-13.

36. Duarte AT, Machado HS. Postoperative pulmonary complications: an epidemiological, risk factors, and prevention Review. J Anesth Clin Res. 2016;7:1.

37. Renee Havey, Emily Herriman, Denise O'Brien. Guarding the Gut Early Mobility After Abdominal Surgery. Crit Care Nurs Q Vol. 36, No. 1, pp. 63-72.

38. Ajitsaria P, Eissa SZ, Kerridge RK. Risk Assessment. Curr Anesthesiol Rep. 2018;8:1-8.

39. Heger P, Probst P, Wiskemann J, Steindorf K, Diener MK, Mihaljevic AL. A Systematic Review and Meta-analysis of Physical Exercise Prehabilitation in Major Abdominal Surgery (PROSPERO 2017 CRD42017080366). J Gastrointest Surg. 2019.

40. Berkel AEM, Bongers BC, van Kamp M-JS, Kotte H, Weltevreden P, de Jongh FHC, Eijsvogel MMM, Ymenga ANM, Bigirwamungu-Bargeman $M$, van der Palen J, van Det MJ, van Meeteren NLU, Klaase JM. The effects of prehabilitation versus usual care to reduce postoperative complications in high-risk patients with colorectal cancer or dysplasia scheduled for elective colorectal resection: study protocol of a randomized controlled trial. BMC Gastroenterol. 2018;18:29.

41. Boden I, Skinner EH, Browning L, Reeve J, Anderson L, Hill C, Robertson IK, Story D, Denehy L. Preoperative physiotherapy for the prevention of respiratory complications after upper abdominal surgery: pragmatic, doubleblinded, multicentre randomized controlled trial. BMJ. 2017;360:j5916.

42. Doganay E, Moorthy K. Prehabilitation for esophagectomy. J Thorac Dis. 2019;11(Suppl 5):S632-8.

43. Mayo NE, Feldman L, Scott S, Zavorsky G, Kim DJ, Charlebois P, Stein B, Carli $F$. Impact of preoperative change in physical function on postoperative recovery: argument supporting prehabilitation for colorectal surgery. Surgery. 2011;150(3):505-14.

44. Shulman M, Myles P. Measuring perioperative outcome. Curr Opin Anaesthesiol. 2016;29(6):733-8.

45. Moonesinghe SR, Mythen MG, Das P, Rowan KM, Grocott MP. Risk stratification tools for predicting morbidity and mortality in adult patients undergoing major surgery. A systematic qualitative review. Anesthesiology. 2013;119:958-81.

46. Koo CY, Hyder JA, Wanderer JP, Eikermann M, Ramachandran SK. A metaanalysis of the predictive accuracy of postoperative mortality using the American Society of Anesthesiologists' physical status classification system. World J Surg. 2015:39(1):88-103.

47. Stonelake S, Thomson P, Suggett N. Identification of the high-risk emergency surgical patient: which risk prediction model should be used? Ann Med Surg (Lond). 2015;4(3):240-7.

48. Foster CA, Charles EJ, Charles EJ, Florence E, Turrentine M-WS, Kron IL, Jones RS. Development and Validation of Procedure-Specific Risk Score for Predicting Postoperative Pulmonary Complication: A NSQIP Analysis. J Am Coll Surg. 2019;229:355-365.e3.

\section{Publisher's Note}

Springer Nature remains neutral with regard to jurisdictional claims in published maps and institutional affiliations.
Ready to submit your research? Choose BMC and benefit from:

- fast, convenient online submission

- thorough peer review by experienced researchers in your field

- rapid publication on acceptance

- support for research data, including large and complex data types

- gold Open Access which fosters wider collaboration and increased citations

- maximum visibility for your research: over $100 \mathrm{M}$ website views per year

At $\mathrm{BMC}$, research is always in progress.

Learn more biomedcentral.com/submissions 